\title{
Bitkilerde Enzimatik ve Enzimatik Olmayan Antioksidanlar
}

\author{
Oğuz Ayhan KİREÇCİ* \\ Bitlis Eren Üniversitesi, Hizan Meslek Yüksekokulu, Bitkisel ve Hayvansal Üretim Bölümü, Bitlis
}

\begin{abstract}
$\ddot{O} \mathbf{z}$
Canlılar çevresel streslere karşı savunma mekanizmalarına sahiptir. Bu mekanizmalar canlıyı stres şartlarının olumsuz etkilere karşı korur. Stres cevaplarının oluşması karmaşık bir süreçtir. Canlı sistemler stres tiplerine karşı oluşturdukları yanıtların uyumuna göre hayatta kalmayı başarabilirler. Biyolojik sistemlerde stresle mücadele eden en önemli mekanizma antioksidan savunmadır. Hayvanlarda olduğu gibi bitkilerde de antioksdian savunma mevcuttur. Bitkiler gibi biyolojik stres cevaplarını aydınlığa kavuşturmak zordur. Bitkiler; antioksidan sistemleri sayesinde çevresel stresin olumsuz etkilerine karşı mücadele edebilirler. Antioksidan sistem Süperoksit dismutaz, Katalaz, Askorbat peroksidaz, Glutatyon peroksidaz, Glutatyon redüktaz, Dehidroaskorbat redüktaz, Monodehidroaskorbat redüktaz ve Guaiakol peroksidaz gibi enzimler ile Askorbik asit, Glutatyon, $\alpha$-Tokoferol, Karotenoid ve Fenolik bileşikler gibi enzimatik olmayan antioksidanlardan oluşur. Bu derlemede bitkilerde mevcut olan enzimatik ve enzimatik olmayan antioksidanlar açıklanmış ve literatüre katkı amaçlanmıştır.
\end{abstract}

Anahtar kelimeler: Antioksidan sistem, Bitki, Enzimatik antioksidan, Enzimatik olmayan antioksidan, Stres.

\section{Enzymatic and Non-Enzymatic Antioxidants in Plants}

\begin{abstract}
Living things have defense mechanisms against environmental stresses. These mechanisms protect the organism against adverse effects of stress conditions. Stress responses are a complex process. Live systems can survive according to the compatibility of their responses to stress types. Antioxidant defense is the most important mechanism to combat stress in biological systems. As in animals, there is antioxidant defense in plants. It is difficult to clarify biological stress responses such as plants. Plants can fight against the negative effects of environmental stress through their antioxidant systems. The antioxidant system consists of enzymatic antioxidants such as Superoxide dismutase, Catalase, Ascorbate peroxidase, Glutathione peroxidase, Glutathione reductase, Dehydroaskorbate reductase, Monodehydroaskorbate reductase and Guaiacol peroxidase, as well as nonenzymatic antioxidants such as Ascorbic acid, Glutathione, $\alpha$-Tocopherol, Carotenoid and Phenolic compounds. This review, plants' enzymatic and non-enzymatic antioxidants were explained and it was intended to provide contribution to literature.
\end{abstract}

Keywords: Antioxidant system, Enzymatic antioxidant, Non-enzymatic antioxidant, Plant, Stress.

\section{Giriş}

Stres; fiziksel olarak bir varlığa uygulanan birim alan başına güç olarak tanımlanabilir. Stres oluştuğu zaman nesnede bir değişiklik meydana gelebilir. Bitkiler aleminde herhangi bir stres çeşidinin neden olduğu değişimi ölçmek zor olduğundan biyolojik bakımdan stresi tanımlamak zordur. Bir bitki için stres oluşturan şartlar başka bir bitki için normal şartları sağlayabilir. Bu açıdan biyolojik stres; bitkiler gibi biyolojik sistemlerde normal fonksiyonları ve oluşumları olumsuz engelleyen şartlar olarak tanımlanabilir [1-3].

Hücreler plazma membranı ile çevrelerinden ayrılırlar. Hücresel yanıtlar ilk olarak hücre dışındaki molekülleri ile hücre membranı proteinleri arasındaki aktiviteler neticesinde ortaya çıkar. Stres

*Sorumlu yazar: kireccioguzayhan@ gmail.com
Geliş Tarihi: 24.09.2018, Kabul Tarihi: 27.11.2018 
faktörü öncelikle plazma membranı üzerindeki reseptörler tarafından algılanır. Devamında oluşan sinyal G protein aracılıklı uyartılar, kalsiyum, inositol fosfat ve reaktif oksijen türleri (ROT) gibi ikincil mesajcıların üretimini sağlar. Sensör proteinler diğer sensörlerle birlikte ilgili genleri aktive ederek bitkinin strese karşı cevap oluşturmasını ve hayatta kalmasını sağlar. Stres sonucunda absisik asit ve etilen gibi hormonların üretiminde ve çeşitli gen ifadelerinde değişimler meydana gelir [4-6].

Kuraklık, sıcaklık tuzu ve yüksek 1şık gibi çevresel faktörler bitki büyümesini, gelişimini ve verimini etkiler. Bunlardan herhangi biri optimum toleransı aştığında stres durumu ortaya çıkar ki, bu da gelişimsel, yapısal, fizyolojik ve biyokimyasal süreçleri etkiler [7-11]. Abiyotik stresin birincil etkileri iyon dengesizliği ve hiperosmotik streslerdir. Bir bitki abiyotik strese maruz kaldığında, bir takım genler açılır. Böylece bazı stres proteinlerinin seviyelerinin artması sağlanır. Bu proteinler ise streslere belirli bir derecede koruma sağlayabilir [1, 11-13].

Stres sirasında, yüksek enerjili bir duruma sahip olan elektronlar, reaktif oksijen türleri (ROT) oluşturmak için moleküler oksijene (O2) transfer edilir [14]. Tekil oksijen (1O2), süperoksit iyonları (O2-) ve hidrojen peroksit (H2O2) gibi peroksitler en yaygın toksik ROT molekülleridir $[15,16]$. ROT'lar membran lipidleri veya mitokondriyal DNA gibi yüksek moleküllü kütle moleküllerini hedef alarak DNA dahil olmak üzere hemen hemen tüm hücresel makromoleküllere zarar verebilir [17]. Özellikle kromatin organizasyonu ve daha düşük mitokondriyal DNA onarım aktivitelerinin olmamasından dolayı mitokondriyal DNA, nükleer DNA'ya nazaran oksidatif hasara daha duyarlıdır [18]. Stres koşullarında, ROT konsantrasyonu, normal büyüme koşulları sırasında üretilen bazal seviyeye kıyasla kloroplastlar, mitokondri ve peroksizomlarda zarar verici seviyelere yükselir. Stres durumunda $\mathrm{CO} 2$ fiksasyonu sinılıdır, bu da Calvin döngüsü ile karbon indirgemesinde bir azalmaya yol açarak fotosentezde mekanizmasındaki okside NADP+ 'y1 azaltır. Fotosentetik elektron transferi sırasında Ferrodoksin aşırı beslendiğinde; elektronlar, daha agresif oksijen radikalleri üreten zincir reaksiyonlarını tetikleyen Mehler reaksiyonu [19], adı verilen mekanizma tarafindan süperoksit radikalleri (O2•-) oluşturmak üzere PS-I'den oksijene aktarılabilir. Serbest radikallerle indüklenen lipit peroksidasyonu, membran bozulmasında da önemlidir [20]. Çoklu doymamış yağ asitleri bitki zarındaki başlıca yağ asitleridir. $\mathrm{Bu}$ doymamış yağ asitleri özellikle $1 \mathrm{O} 2$ ve $\mathrm{HO}$ • gibi moleküllere karş1 duyarlıdırlar [21]. Geniş kapsamdaki çoklu doymamış yağ asitleri peroksidasyonu membranın akışkanlığını azaltır, sızıntıyı artırır ve membran proteinlerinde ikincil hasar meydana getirir [22].

Yaklaşık 2.7 milyar yıl önce çevremizdeki fotosentetik organizmalar tarafindan moleküler oksijen üretilmiştir ve ROT'lar oksijenli hayatın istenmeyen ürünleri olmuştur [6, 22]. DNA, birçok farklı yolla ROT tarafından değiştirilebilir. ROT'lar içinde HO• en reaktif olanı iken, $1 \mathrm{O} 2$ esas olarak guanine saldırır. $\mathrm{H} 2 \mathrm{O} 2$ ve $\mathrm{O} 2 \bullet-$ daha iyimser olanlarıdır [23]. 8-Hidroksiguanin en sık gözlenen modifikasyondur [11, 24]. Protein oksidasyonu, ROT veya oksidatif stresin yan ürünleri tarafindan indüklenen bir proteinin kovalent modifikasyonu olarak tanımlanır. Çoğu protein oksidasyonu temelde geri dönüşümsüzdür, ancak kükürt içeren amino asitlerden birkaç tanesi tersine çevrilebilir [25]. Protein oksidasyonu yaygındır ve sıklıkla oksidatif stres için tanısal bir belirteç olarak kullanılır. ROT ağırlıklı olarak hücre hasarına neden olmakla birlikte hücre içi sinyalleme ve düzenlemenin çeşitli yönlerinde önemli bir fizyolojik rol oynamaktadır [26]. ROT'un bir dizi genin ve sinyal transdüksiyon yollarının ekspresyonuna müdahale ettiğini açıkça ortaya koymuştur [12, 27, 28]. ROT, ikincil haberci olarak çok önemli bir fizyolojik rol oynayabilir. ROT'un toksik etkileri süperoksit dismutaz (SOD), katalaz (CAT), askorbat peroksidaz (APX), glutatyon redüktaz (GR), askorbik asit (AsA) gibi enzimatik olan ve tokoferol, glutatyon ve fenolik bileşikler gibi enzimatik olmayan antioksidatif sistem ile de karş1 karşıyadır [28-33]. Normal olarak, her hücresel kısım belirli bir ROT'u detoksifiye eden birden fazla enzimatik aktivite içerir. Örneğin, sitozol H2O2'yi temizleyen APX, GPX ve PrxR gibi en az üç farklı enzim içerir [34].

Oksidatif hasarın ana nedeni, bir antioksidan sistem tarafindan önlenebilen mitokondriyadaki elektron taşıma sistemi (ETS) ürünü olarak reaktif oksijen türlerinin (ROT) üretilmesidir. Antioksdain sistem içerisindeki SOD enzimi süperoksit radikallerini yok ederken Katalaz, hidrojen peroksidin su ve oksijen içinde değişimini katalize eder [35]. Glutatyon peroksidaz radikal süpürücü ve membran stabilizörü olarak görev yapar. Askorbat oksidaz askorbik asit içeren bir redoks sistemine katılarak oksitlenmiş ve indirgenmiş glutatyon ve NADPH düzeylerini düzenleyebilir [36]. Polifenol oksidaz bazı fenolik bileşiklerin kinonlara aerobik oksidasyonunu katalize eder ve kloroplastlarda $\mathrm{H} 2 \mathrm{O} 2$ ile su stresine karşı savunma yapar [37]. Aşırı peroksidasyon, E vitamini ve C vitamini gibi antioksidanların 
geri dönüşümü için gerekli olan artan glutatyon tüketimine neden olur. C vitamini suda çözünür bir antioksidandır, peroksiradikalleri temizler [38].

ROT'lar hücrede; kloroplastlar, mitokondri, peroksizomlar, plama membranları, endoplazmik retikulum ve hücre duvarının çeşitli yerlerinde hem normal hem de stresli koşullarda üretilmektedir. Işık varlığında, kloroplastlar ve peroksizomlar, ROT üretiminin ana kaynaklarıdır. Mitokondri ise karanlık koşullar altında ROT'un lider üreticisidir [39]. Aerobik organizmalar reaktif oksijen türlerinin sebep olduğu toksisiteye karşı hem kimyasal hem de enzimatik korunma sistemlerine sahiptir [40, 41].

\section{Enzimatik Antioksidanlar}

\subsection{Süperoksit Dismutaz (SOD)}

Süperoksit dismutaz enzimi $\mathrm{O}_{2}{ }^{-9}$ yi $\mathrm{H}_{2} \mathrm{O}_{2}$ 'ye dönüştürür ve ilk olarak altı genetik ve biyokimyasal olarak ayrı izozimleri içeren mısırda gösterilmiştir [42, 43]. Aktif bölgelerindeki metal iyonu temelinde SOD, bakır ve çinko (Cu / Zn SOD), manganez (MnSOD) veya demir içermesine (FeSOD) göre çeşitli tipleri vardır. Aktif merkezde Ni içeren başka bir SOD tipi Streptomyces'te keşfedilmiştir [44]. Cu/ZnSOD, bitki hücresinin sitosol ve kloroplastında bulunur, MnSOD, mitokondri ve peroksizomların matriksindedir. SOD'ların düzenlenmesi, abiyotik strese bağlı olarak ortaya çıkan oksidatif stresle mücadelede rol oynamaktadır ve bitkilerin hayatta kalmasında önemli bir role sahiptir. Deneysel sonuçlar tuz stresi altındaki buğday, bezelye, mısır ve çay bitkilerinde SOD aktivitesinde artış olduğunu göstermektedir [45-47]. Süperoksid dismutaz, $\mathrm{O}_{2}{ }^{-}$anyonunu, daha az reaktif türler olan $\mathrm{O}_{2} \mathrm{ve} \mathrm{H}_{2} \mathrm{O}_{2}$ 'ye dönüştürür. SOD enzimi aktif bölgesinde bulunan metal kofaktörlere göre $\mathrm{Fe}-\mathrm{SOD}, \mathrm{Mn}-\mathrm{SOD}$ ve $\mathrm{Cu} / \mathrm{Zn}$ SOD olarak üç tipte sinıflandırılır. Mantarlarda ve hayvanlarda yalnızca $\mathrm{Cu} / \mathrm{Zn}$-SOD ve Mn-SOD bulunurken, bazı bitki türlerinde ve bakterilerde üç izoenzim tipi de bulunmaktadır. Bitkilerde SOD izoenzimleri farklı hücre bölümlerinde yer alır. Fe-SOD genelde bitkilerde belirlenememelerine karşın tespit edildikleri zaman kloroplast kısımlarında, Mn-SOD mitokondri ve peroksizomlarda, $\mathrm{Cu} / \mathrm{Zn}-\mathrm{SOD}$ kloroplast, sitoplazma ve hücrelerarası boşlukta bulunur [14, 48-51]. SOD izo enzimlerinin aktiviteleri, negatif boyanmaları ve potasyum siyanür $(\mathrm{KCN})$ ve hidrojen perokside duyarlılıklarına göre belirlenir. SOD'un enzimatik reaksiyonu sonucu $\mathrm{H}_{2} \mathrm{O}_{2}$ ve $\mathrm{O}_{2}$ oluşur $[42,48]$. Oluşan $\mathrm{H}_{2} \mathrm{O}_{2}$ 'nin hücreye zarar vermemesi için hemen ortamdan uzaklaştırılması gereklidir. Çünkü $\mathrm{H}_{2} \mathrm{O}_{2}$ belirli metal iyonları ve şelatların varlığında yüksek derecede reaktif $\mathrm{OH}$ radikalini oluşturur. Süperoksit dismutaz çeşitlerinin düzenlenmesi biyotik ve abiyotik streslerin neden olduğu oksidatif stres ile mücadelede ve çevresel stres şartları altındaki bitkinin hayatta kalabilmesinde hayati rol oynar [51]. Çeşitli çevresel stres şartları reaktif oksijen türlerinin üretiminde artışa neden olurken süperoksit dismutaz enzimi reaktif oksijen türlerinin miktarlarının azaltılmasında ve bertaraf edilmesinde önemli bir antioksidandır. Moleküler oksijenin çevresindeki moleküllerden iki elektron alması veya süperoksidin bir elektron alması sonucu peroksit meydana gelir. SOD dismutasyonla $\mathrm{O}_{2}{ }^{--}$molekülünü uzaklaştırır. Peroksit molekülü de iki hidrojen atomu ile birleşerek hidrojen peroksidi $\left(\mathrm{H}_{2} \mathrm{O}_{2}\right)$ oluşturur $[40,52] . \mathrm{H}_{2} \mathrm{O}_{2}$ membranlardan geçebilen uzun ömürlü bir oksidandır. Kendisi bir serbest radikal olmadığı halde, reaktif oksijen türleri içine girer ve serbest radikal biyokimyasında önemli rol oynar. Geçiş metal iyonları varlığında daha da hızla gerçekleşen bir reaksiyonla süperoksit anyon radikali ile birlikte en reaktif radikal olan hidroksil radikalini oluşturur $[41,53]$. Süperoksit radikalinin konsantrasyonu, yüksek katalitik etkiye sahip süperoksit dismutaz (SOD) enziminin etkisiyle azaltılır. SOD tarafindan katalizlenen bu reaksiyona dismutasyon tepkimesi adı verilir [41, 54].

\subsection{Katalaz (CAT)}

Esas olarak peroksizomlarda lokalize olan katalazlar, $\mathrm{H}_{2} \mathrm{O}_{2}{ }^{\prime} \mathrm{yi}_{2} \mathrm{O}_{2}$ ve $\mathrm{H}_{2} \mathrm{O}^{\prime}$ ya dönüştüren tetramerik hem içeren enzimlerdir [55, 56]. Bitki katalazları üç sınıfa ayrılabilir. 1. sınıf katalazlar fotosentetik dokularda en belirgindir ve foto-respirasyon sirasinda üretilen $\mathrm{H}_{2} \mathrm{O}_{2}$ 'nin giderilmesinde rol oynar. 2. sinıf katalazlar vasküler dokularda yüksek oranda üretilir ve lignifikasyonda rol oynayabilir. 3. sınıf katalazlar ise, tohumlar ve genç bitkilerde oldukça fazladır ve bunların aktiviteleri glioksizomlarda glioksilat çevrimi sırasında yağ asidi bozunması sırasında üretilen aşırı $\mathrm{H}_{2} \mathrm{O}_{2}$ 'nin uzaklaştırılması ile bağlantılıdır [57]. Katalazlar, $\mathrm{H}_{2} \mathrm{O}_{2}$ 'yi doğrudan değiştirebilen ve stres sırasında ROT detoksifikasyonu için vazgeçilmez olan başlıca temizleyici enzimlerdir [58]. Katalaz aktivitesindeki artışın, muhtemelen 
$\mathrm{H}_{2} \mathrm{O}_{2}$ 'nin toksik seviyelerini azaltarak doku metabolizmasındaki hasarın üstesinden gelmeye yardımc1 olan bir özelliği olduğu düşünülmektedir. Abiyotik stres, çay, pamuk ve tütünde katalazın ekspresyonundan sorumlu genlerin düzenlenmesine yol açmaktadır [47, 59, 60]. Zhang ve ark., [61], 2. sınıfta yer alan katalazların temel olarak hastalık gelişimi ve direnciyle ilişkili olduğunu belirtmiştir. SA (salisilik asit) için bir hedef olduğu ve transgenik patates bitkilerinde tütün Cat2Nt geninin ekspresyonu, endojen patates Cat2St geninin kurucu ekspresyonuna ve duyarlı patates bitkilerinde Phytophthora infestans'a karşı arttırılmış dirence yol açabilir [62].

\subsection{Glutatyon Peroksidaz (GPx)}

Glutatyon peroksidazlar, $\mathrm{H}_{2} \mathrm{O}_{2}$ ve sitotoksik hidroperoksitlerin alkollere indirgenmesini katalizleyen çoklu izozimlerin ailesidir [63]. Bu nedenle, $\mathrm{H}_{2} \mathrm{O}_{2}$ 'nin atılmasının yanı sıra, GPx'ler ayrıca lipit ürünlerinin detoksifiye edilmesine de hizmet eder. ROT aktivitesi nedeniyle peroksidasyon oluşur. Bitkilerde GPx'ler; selenyum bağımlı GPx, nonselenium bağımlı fosfolipitler hidroperoksit GPx (PHGPX) ve GPX aktivitesini gösteren glutatyom transferazlar (GST) olmak üzere üç tip olarak sınıflandırılır: GPx ve GST enzimleri alt ünitelerinde, selenyumun aktif merkezdeki bağlanma yapısında ve katalitik mekanizmalarında farklılık gösterir. Glutatyon peroksidaz geni veya glutatiyon S-transferaz geninin herhangi birinin aşırı ekspresyonu, E. coli'de tekil oksijen direncini arttırmak için yeterli olmuştur [64GPx'in katalitik reaksiyonu için substrat, $\mathrm{H}_{2} \mathrm{O}_{2}$ veya organik bir peroksit olan ROOH'1 kullanır. GPx, aynı anda GSH'yi oksitlerken peroksitleri suya (veya alkole) ayırır. GPx, bir substrat olarak $\mathrm{H}_{2} \mathrm{O}_{2}$ için katalaz ile rekabet eder ve düşük seviyelerde oksidatif strese karşı ana koruma kaynağıdır.

\subsection{Askorbat Peroksidaz (APX)}

APX, $\mathrm{H}_{2} \mathrm{O}_{2}$ 'nin su-su ve askorbat-glutatyon döngülerinde tutulmasıyla ilgilenir ve askorbik asidi (AsA) elektron vericisi olarak kullanır. APX'ler (askorbat peroksidazlar) $\mathrm{H}_{2} \mathrm{O}_{2}$ 'yi suya indirir ve bitkilerin antioksidan sisteminde önemli bir rol oynar. [65, 66]. APX ailesi, thylakoid ve mikrozomal membran bağlı formlarda bulunabildiği gibi çözünür formda stromal, sitosolik ve apoplastik enzimleri de içeren en az beş farklı izoformdan oluşur [67]. APX'in kloroplastik izoformu çok kararsızdır ve yarı ömrü AsA'nın yokluğunda 30 saniyeden azdır. Sitozolik formun yarı ömrü ise 40-60 dakikadır [68]. APX 1spanak, bezelye, çay ve soya fasülyesinde belirlenmiştir. Thylakoidal APX, stres altında nanomolar seviyelerde $\mathrm{H}_{2} \mathrm{O}_{2}$ tarafından inhibe edilir [68, 69]. APX, $\mathrm{H}_{2} \mathrm{O}_{2}$ için CAT'ten daha yüksek bir afiniteye sahiptir ROT sinyallemesinin ince modülasyonundan sorumlu olabilir. Zhang ve ark., [61], 9sispoksikrotenoid dioksijenaz (NCED) geni SgNCED1'i aşırı eksprese eden transgenik tütünün, APX'in artan aktivitesini gösterdiğini ve transjenik bitkilerin, $0.1 \mathrm{M}$ mannitol indüklenmiş kuraklık stresi ve 0.1 $\mathrm{M} \mathrm{NaCl}$ kaynaklı tuzluluk stresi altında büyümeyi geliştirdiğini bildirmiştir. Vital ve ark., [60], $\mathrm{NaCl}$ ve parakuat stresi altındaki pamuk kalluslarında askorbat peroksidaz (APX) aktivitelerinin 2 saat içinde önemli ölçüde arttığını göstermiştir. Buğday bitkisinde $300 \mathrm{mM} \mathrm{NaCl}$ stresinin APX aktivitesini ciddi derecede artırdığı bildirilmiştir [45]. APX ile ilşikili genler çeşitli abiyotik streslere karşı farklı şekilde modüle edilir [70-72].

\subsection{Glutatyon Redüktaz (GR)}

GR bir dizi bitki dokusundan arındırılmış ve oldukça korunmuş bir enzimdir. GSSG'nin disülfit bağının NADPH-bağımlı reaksiyonunu katalize eder ve bu nedenle indirgenmiş glutatyon havuzunu korumak için önemlidir. GR esas olarak kloroplast stromada lokalize olmakla birlikte, mitokondri, sitosol ve peroksizomlarda da bulunur. Bitkiler bu enzimin birden çok formuna sahiptir [73]. GR, askorbatglutatyon yolunun son adımını sınırlayan hızı katalize eder. Yüksek seviyeli GR aktivitesi muhtemelen $\mathrm{NADP}^{+} /$NADPH oranını artırarak NADP+'nın fotosentetik elektron taşıma zincirinden elektronları kabul etmesi sağlamaktadır. Böyle bir durumda elektronların $\mathrm{O}_{2}$ 'ye akışı ve dolayısıyla $\mathrm{O}_{2}$ 'nin oluşumu minimize edilebilir [74]. GR'de artış bitkilerde aktivite, glutatyon (GSH) seviyelerinin birikmesine neden olur ve sonuç olarak bitkilere tolerans sağlar. 


\subsection{Dehidroaskorbat Redüktaz (DHAR)}

Bir elektron vericisi olarak redüklenmiş glutatyon (GSH) kullanalarak dehidroaskorbatı (DHA) AsA'ya düşürür [75]. Hem simplast hem de apoplastta AsA havuz büyüklügünün düzenlenmesi kritiktir, böylece bitki hücresinin redoks durumunu ana hatlarıyla incelenebilir [76]. DHAR bol miktarda tohumlarda, köklerde ve yeşil filizlerde bulunur. Çeşitli bitkilerin dokularında DHAR aktivitesi olduğu da bildirilmiştir [77].

\subsection{Monodehidroaskorbat Redüktaz (MDHAR)}

MDHAR kısa ömürlü Monodehidroaskorbat (MDHA)'dan, NADPH'yi bir indirgeyici ajan olarak kullanarak, nihai olarak hücresel AsA havuzunun yenilenmesinden sorumludur. AsA'y1 yeniden oluşturduğundan, APX ile peroksizomlar ve mitokondrilerde lokalizedir. APX, $\mathrm{H}_{2} \mathrm{O}_{2}$ 'yi süpürür ve bu işlemde AsA'y1 oksitler [14]. MDHAR, kloroplast, mitokondri, peroksizomlar, sitosol ve glioksisomlarda bulunur ve çeşitli izozimlere sahiptir. MDAR izoformlarının kloroplast, sitozol, peroksizom ve mitekondride bulunduğu belirtilmiştir [78, 79].

\subsection{Guaiakol Peroksidaz (GPX)}

Hem normal metabolizma sırasında hem de stres sırasında aşırı $\mathrm{H}_{2} \mathrm{O}_{2}$ 'yi ortadan kaldıran 40-50 kDa monomerlerden oluşan hem içeren bir enzimdir. Lignin biyosentezinde hayati bir rol oynar ve indol asetik asidi (IAA) bozarak ve $\mathrm{H}_{2} \mathrm{O}_{2}$ 'yi de kullanarak biyotik strese karşı savunur. GPX, guaiakol ve pyragallol [80]. gibi aromatik bileşikleri elektron donörü olarak tercih eder. GPX'in, hücre duvarında (sitosol, vakuol) aktif olduğu ve hücre duvarında aktif olduğu için $\mathrm{H}_{2} \mathrm{O}_{2}$ 'nin çıkarılmasında anahtar enzim olarak kabul edilir.

\section{Enzimatik Olmayan Antioksidanlar}

\subsection{Askorbik Asit (AsA)}

AsA, en kapsamlı olarak çalışılan antioksidanlardan biridir ve bitki hücre tipleri, organel ve apoplastların çoğunda saptanmıştır [81, 82]. Normalde, indirgenmiş formda oluşur ve hücre içi konsantrasyonu 20 mM'dan 300 mM'ye kadar değişir (Noctor ve Foyer, 1998). Askorbat, mitokondride sentezlenir ve bir proton-elektrokimyasal mekanizma veya kolaylaştırılmış difüzyon yoluyla diğer hücre bileşenlerine taşınır [81]. AsA; bitkilerin büyümesi, farklılaşması ve metabolizmasını düzenleyen birçok fizyolojik sürece etki eder [83]. AsA'nın bitki savunma sisteminde önemli bir rolü de hücrenin metabolik süreçlerini $\mathrm{H}_{2} \mathrm{O}_{2}$ ve diğer toksik oksijen türevlerine karşı korumaktır. AsA esas olarak indirgeyici olarak hareket eder ve birçok serbest radikal türünü temizler. Malondialdehit (MDA) sürecinde etkildir. Elektron donörü genellikle NADPH'dır ve kloroplastlarda su-su döngüsü durumunda monodehidroaskorbat redüktaz (MDAR) veya ferredoksin ile katalize edilir [80]. AsA, ${ }^{1} \mathrm{O}_{2}, \mathrm{O}_{2}{ }^{--}$ve OH'yi doğrudan süpürüp tokoferoksil radikalinden tokoferolü geri kazanarak membran koruması sağlar. AsA ayrıca, ketenepoksidazın kofaktörü olarak davranır, böylece aşırı uyarım enerjisinin yayılmasını sağlar [82]. $\alpha$-tokoferolü rejenere ederek veya ksantofil siklusundaki zeaksantinin senteziyle dolaylı olarak reaksiyona girebilir. AsA, oksidatif sürecin neden olduğu hasarı en aza indirmede büyük rol oynamaktadır. Bunu diğer antioksidanlarla olan sinerjik etkisi ile gerçekleştirilir [84].

\section{2. $\alpha$-Tokoferol}

Tokoferoller; bitkilerin ve alglerin tüm kısımlarında bulunan bir antioksidan ailesidir [55]. Dört izomerden $(\alpha, \beta, \gamma$ ve $\delta)$ oluşan [85] tokoferoller içerisinde $\alpha$-tokoferoller, kloroplast membranlardaki en biyolojik olarak aktif ve baskın antioksidandır. Böylece foto-oksidatif hasara karşı koruyucu etki gösterir. Antioksidan özellikler tekil oksijeni bağlama yeteneğine bağlıdır. Wu ve Tang [86], 120 tekli oksijen molekülünün tek bir $\alpha$-tokoferol molekülü tarafından nötralizeedilebileceğini ileri sürmektedir. $\alpha$-tokoferoller ayrıca lipit oksidasyonu ile üretilen çoklu doymamış yağ asitleri radikallerini içeren zincir reaksiyonlarda sonlandırıcılar olarak işlev görür [87]. $\alpha$-Tokoferoller lipit peroksi radikallerini 
süpürür ve askorbat veya diğer antioksidanlarla reaksiyona sokar [88]. Tokoferollerin en önemli işlevi, çoklu doymamış yağ asitleri ile ilgili çeşitli mekanizmalara katılmalarıdır [64]. Fotosentez ve metabolizmanın yan ürünleri olarak üretilen ROT, bitki hücrelerinde potansiyel lipit peroksidasyonu kaynaklarıdır. Çeşitli abiyotik streslere yanıt olarak fotosentetik bitki dokularında $\alpha$-Tokoferol düzeyleri artmaktadır [89]. $\alpha$-Tokoferoller çeşitli ROT ve lipit oksidasyon ürünlerini temizler ve söndürür, membranları stabilize eder ve sinyal iletimini modüle eder [89, 90]. $\alpha$-Tokoferoller, lipit otooksidasyonunda etkili bir serbest radikal tuzağı oluşturur. AsA ile birlikte tokoferollerdeki artış, pirinçteki su eksikliği koşullarının birincil tepkilerinden biri olarak ortaya çıkmıştır [91]. Oksidatif stres yüksek bitkilerde tokoferol sentezinden sorumlu genlerin ifadesini aktive eder. $\alpha$-tokoferol ve askorbik asit içeren antioksidanların domateste triazol uygulamasını takiben arttığı bildirilmiştir ve bu moleküller membranların oksidatif hasara karşı korunmasında rol oynayabilir [92]. Triazol, buğdayda antioksidan ve antioksidan enzimlerin seviyelerini arttırmaktadır [93]. Bitkilerde su stresi sirasinda tokoferolde artışlar birçok araştırmacı tarafından gösterilmiştir $[92,94]$.

\subsection{Glutatyon}

Glutatyon; sitosol, kloroplastlar, endoplazmik retikulum, vakuoller ve mitokondri gibi hemen hemen tüm hücre bölümlerinde saptanan bir tripeptit ( $\gamma$-glutamilsisteinil glisin)'dir [95]. Glutatyon, çoğu bitki hücresinde ana protein olmayan tiol kaynağıdır. Glutatyonun tiol grubunun kimyasal reaktivitesi, tüm organizmalarda geniş bir biyokimyasal fonksiyon yelpazesine hizmet etmeyi özellikle uygun kılmaktadır. Tiol grubunun nükleofilik yapısı, metallerle merkapid bağlarının oluşmasında ve seçilen elektrofillerle reaksiyona girmesinde önemlidir. Ayrıca ağılıklı olarak indirgenmiş formda (GSH) oluşur ve konsantrasyonu kloroplastlarda en yüksektir (1-4 mM). Glutatyonun biyosentetik yolu iyi bilinmektedir ve askorbat biyosentezden farklı olarak bitkiler, hayvanlar ve mikroorganizmalarda benzerdir. AT-glutamilsistein sintetaz ( $\gamma$-ECS) ve glutatyon sentetaz (GSHS) ile katalizlenen ATP'ye bağlı iki aşamada bileşen amino asitler tam tripeptidi oluşturmak üzere bağlanır. Bu adımlar hem kloroplastik hem de kloroplastik olmayan bölmelerde meydana gelir ve sinapslarda glutatyon konsantrasyonları ve redoks durumundaki değişiklikler önemli olabilir [96]. Glutatyon, çeşitli yollarla etki eden bir antioksidandır. Askorbat-glutatyon çevriminde GSH, hem enzimatik hem de enzimatik olmayan DHA'yı (dehidroaskorbat) azaltmak için kullanılır ve kendisi GSSG'ye (oksitlenmiş glutatyon) oksitlenir. GSSG'den GSH'ye rejenerasyon, glutatyon redüktaz ile katalize edilir ve NADPH indirgeme gücü olarak kullanılır. GSH'nin yüksek redüksiyon potansiyelinden merkezi bir nükleofilik sistein kalıntısı sorumludur. GSH'nin antioksidatif savunmadaki bu merkezi rolü, bir başka güçlü antioksidan, askorbik asidi askorbat-glutatyon döngüsü yoluyla yeniden üretme yeteneğinden kaynaklanmaktadır [95].

\subsection{Karotenoid}

Karotenoidler; bitkilerde ve mikroorganizmalarda bulunan pigmentlerdir. Doğada meydana gelen 600 'den fazla karotenoid vardır. Çeşitli çalışmalar, karotenoidlerin belirli kanser türlerini, aterosklerozu, yaşa bağlı kas dejenerasyonunu ve diğer hastalıkları önleyebileceğini veya önlediğini göstermiştir. Karotenoidlerin antioksidan aktivitesi, esas olarak $\beta$-karotenin bozulma olmaksızın tekil oksijeni baskılamaya yönelik mükemmel kabiliyetinden sorumlu olan, eşlenmemiş elektronları delokalize etmek için konjuge çift bağlı yapı yeteneğinin bir sonucu olarak ortaya çıkar. Peroksil (ROO), hidroksil $(\mathrm{OH})$ ve süperoksit radikalleri $\left(\mathrm{O}_{2}{ }^{-*}\right)$ gibi serbest radikallerle $\beta$-karoten kimyasal reaktivite gösterir. Yeterince yüksek konsantrasyonlarda, karotenoidler lipitleri peroksidatif hasara karşı koruyabilir [97].

\subsection{Fenolik Bileșikler}

Flavonoidler, tanenler, hidroksisinnamat esterler ve lignin gibi fenolikler, bitki dokularında bol miktarda bulunan çeşitli ikincil metabolitlerdir. Polifenoller serbest radikal temizleme aktivitesi için ideal bir yapısal kimyaya sahiptirler. Tokoferol ve askorbattan daha etkili antioksidanlar olduğu gösterilmiştir. Polifenolik bileşikler en yaygın olarak ortaya çıkan ve her yerde bulunan bitki metabolitleri gruplarından birini oluşturur ve insan diyetinin ayrılmaz bir parçasını temsil eder [98]. Polifenollerin antioksidatif özellikleri, hidrojen veya elektron donörleri olarak yüksek reaktifliklerinden ve polifenol türevli 
radikalin stabilize olma yeteneklerinden kaynaklanır. Eşlenmemiş elektronu (zincir kırma fonksiyonu) ve geçiş metali iyonlarını şelatlama Fenton reaksiyonunun sonlandırılması) yeteneklerine sahiptirler [99]. Fenoliklerin antioksidatif özelliklerinin altında yatan bir başka mekanizma da lipid metabolizması modifikasyonu ve zarların akışkanlığının azaltılması ile flavonoidlerin peroksidasyon kinetiğini değiştirebilmeleridir. $\mathrm{Bu}$ değişiklikler, serbest radikallerin difüzyonunu olarak engelleyebilir ve peroksidatif reaksiyonları kısıtlayabilir. Antioksidanlar olarak işlev gören fenolik bileşikler, serbest radikal zincirlerinin sonlandırıcıları ve lipid peroksidasyonunu katalize edebilen redoks-aktif metal iyonlarının bağlayıcıları olarak işlev görebilir [98].

\section{Sonuç ve Öneriler}

Çeşitli stres tiplerinin sebep olduğu ROT'lar hücre ve organizmaya ciddi zararlar vermektedir. Özellikle hücre membranındaki çoklu doymamış yağ asitlerinde meydana gelen zararlar oldukça önemlidir. Bitkiler sahip oldukları antioksidan savunma sistemi ile stres cevapları oluşturmakta ve stresin neden olduğı olumsuz durumlarşla başa çıkabilmektedir. ROT'lar canlıda bir takım sinyal yollarını uyarmakra ve kompleks mekanizmalarla antioksidan savunma başlatılmaktadır. Canlılarda antioksidanlar yaşam için çok önemli moleküllerdir. Enzimatik ve enzimatik olmayanlar antioksidanlar canlının normal yaşam faaliyetlerini sürdürmesine yardımcı olmaktadır. Bu sistemler bir bir ile iletişim ve etkileşim içinde hareket etmektedir. Strese cevap olarak ortay konan tepkiler bu mekanizmaların ortak ve uyum içerisinde çalışmasıyla mümkündür. Stres uyartısı alındığı zaman ilgili reseptörler ve genler yeniden düzenlenerek cevapları oluşturmakta ve antioksidan moleküller görevlerini yapmaktadır. Çevresel stresler bitkilerde ürün ve verim kaybına neden olan en önemli unsurlardan biridir. Bu nedenle bitkilerde antioksidan savunma üzerine yapılan çalışmalar durmadan devam edecektir. Söz konusu antioksidan savunma mekanizmasının daha iyi anlaşılması için gen ifadelerinin açıklığa kavuşturulması daha etkili olacaktır.

\section{Kaynaklar}

[1] Jaleel C.A., Manivannan P., Wahid A., Farooq M., Al-Juburi H.J., Somasundaram R., Panneerselvam R. 2009. Drought Stress in Plants: A Review on Morphological Characteristics and Pigments Composition. International Journal of Agricultural Biology, 11: 1.

[2] Gaspar T., Franck T., Bisbis B., Kevers C., Jouve L., Hausman J.F., Dommes J. 2002. Concepts in Plant Stress Physiology. Application to plant tissue cultures. Plant Growth Regulation, 37: 263285.

[3] Jones H.G., Jones M.B. 1989. Introduction: some terminology and common mechanisms, in: Jones H.G., Flowers T.J., Jones M.B. (Eds.), Plants Under Stress, Cambridge university Press, Cambridge, 1-10.

[4] Shinozaki K., Yamaguchi-Shinozaki K. 2007. Gene networks involved in drought stress response and tolerance. Journal of Experimental Botany, 58 (2): 221-227.

[5] Yamaguchi-Shinozaki K., Shinozaki K. 2005. Organization of cisacting regulatory elements in osmotic- and cold-stress-responsive promoters. Trends in Plant Science. 10: 88-94.

[6] Mahajan S., Tuteja N. 2005. Cold, salinity and drought stresses: an overview. Archives of Biochemistry and Biophysics, 444 (2): 139-158.

[7] Jaleel C.A., Gopi R., Manivannan P., Gomathinayagam M., Murali P.V., Panneerselvam R. 2008c. Soil applied propiconazole alleviates the impact of salinity on Catharanthus roseus by improving antioxidant status. Pesticide Biochemistry and Physiology, 90 (2): 135-139.

[8] Jaleel C.A., Manivannan P., Lakshmanan G.M.A., Gomathinayagam M., Panneerselvam R. 2008a. Alterations in morphological parameters and photosynthetic pigment responses of Catharanthus roseus under soil water deficits. Colloids and Surfaces B: Biointerface, 61 (2): 298-303.

[9] Jaleel C.A., Manivannan P., Murali P.V., Gomathinayagam M., Panneerselvam R. 2008d. Antioxidant potential and indole alkaloid profile variations with water deficits along different parts of two varieties of Catharanthus roseus. Colloids and Surfaces B: Biointerface, 62: 312-318.

[10] Jaleel C.A., Sankar B., Murali P.V., Gomathinayagam M., Lakshmanan G.M.A., Panneerselvam R. 2008b. Water deficit stress effects on reactive oxygen metabolism in Catharanthus roseus; impacts on ajmalicine accumulation. Colloids and Surfaces B: Biointerface, 62 (1): 105-111. 
[11] Tuteja N., Ahmad P., Panda B.B., Tuteja R. 2009. Genotoxic stress in plants: shedding light on DNA damage, repair and DNA repair helicases. Mutation Reserachs, 681: 134-149.

[12] Ahmad P., Sarwat M., Sharma S. 2008a. Reactive oxygen species, antioxidants and signaling in plants. Journal of Plant Biology, 51 (3): 167-173.

[13] Bhatnagar-Mathur P., Vadez V., Sharma KK. 2008. Transgenic approaches for abiotic stress tolerance in plants: retrospect and prospects. Plant Cell Reports, 27: 411-424.

[14] Mittler R. 2002. Oxidative stress, antioxidants and stress tolerance. Trends in Plant Science. 7: 405410.

[15] Apel K., Hirt H. 2004. Reactive oxygen species: metabolism, oxidative stress, and signal transduction. Annual Review of Plant Biology, 55: 373-399.

[16] Triantaphylides C., Krischke M., Hoeberichts F.A., Ksas B., Gresser G., Havaux M., Van Breusegem F., Mueller M.J. 2008. Singlet oxygen is the major reactive oxygen species involved in photooxidative damage to plants. Plant Physiology, 148: 960-968.

[17] Tuteja N., Sopory S.K. 2008. Plant signaling in stress: G-protein coupled receptors, heterotrimeric G-proteins and signal coupling via phospholipases. Plant Signalling and Behavior, 3: 79-86.

[18] Yakes F.M., Van Houten B. 1997. Mitochondrial DNA damage is more extensive and persists longer than nuclear DNA damage in human cells following oxidative stress. Proceedings of the National Academy of Sciences of the United States of America, 94: 514-519.

[19] Hsu S.Y., Kao C.H. 2003. The protective effect of free radical scavengers and metal chelators on polyethylene glycol-treated leaves. Biologia Plantarum, 46: 617-619.

[20] McCord J.M. 2000. The evolution of free radicals and oxidative stress. American Journal of Medicine, 108: 652-659.

[21] Mueller M.J. 2004. Archetype signals in plants: the phytoprostanes. Current Opinion in Plant Biology, 7: 441-448.

[22] Halliwell B. 2006. Reactive species and antioxidants. Redox biology is a fundamental theme of aerobic life. Plant Physiology, 141: 312-322.

[23] Wiseman H., Halliwell B. 1996. Damage to DNA by reactive oxygen and nitrogen species: role in inflammatory disease and progression to cancer. Biochemistry Journal, 313 (1): 17-29.

[24] Jaleel C.A., Gopi R., Manivannan P., Panneerselvam R. 2008h. Exogenous application of triadimefon affects the antioxidant defense system of Withania somnifera Dunal. Pesticide Biochemistry and Physiology, 91 (3): 170-174.

[25] Ghezzi P., Bonetto V. 2003. Redox proteomics: identification of oxidatively modified proteins. Proteomics, 3: 1145-1153.

[26] Palmer H.J., Paulson K.E. 1997. Reactive oxygen species and antioxidants in signal transduction and gene expression. Nutritions Reviews, 55: 353-361.

[27] Thannickal V.J, Fanburg B.L. 2000. Reactive oxygen species in cell signaling. American Journal of Physiology-Lung Cellular and Molecular Physiology, 279: L1005-L1028.

[28] Jaleel C.A., Gopi R., Manivannan P., Gomathinayagam M., Hong-Bo S., Zhao C.X., Panneerselvam R. 2008i. Endogenous hormonal and enzymatic responses of Catharanthus roseus with triadimefon application under water deficits. Comptes Rendus Biologies, 331: 844-852.

[29] Scandalios J.G. 2005. Oxidative stress: molecular perception and transduction of signals triggering antioxidant gene defenses. Brazilian Journal of Medicical Biological Researchs, 38 (7): 995-1014.

[30] Gratao P.L., Polle A., Lea P.J., Azevedo R.A. 2005. Making the life of heavy metal-stressed plants a little easier. Functional Plant Biology, 32 (6): 481-494.

[31] Shi Q.H., Zhu Z.J. 2008. Effects of exogenous salicylic acid on manganese toxicity, element contents and antioxidative system in cucumber. Environental and Experimental Botany, 63: 317326.

[32] Sharma S.S., Dietz K.J. 2009. The relationship between metal toxicity and cellular redox imbalance. Trends in Plant Science, 14: 43-50.

[33] Ashraf M. 2009. Biotechnological approach of improving plant salt tolerance using antioxidants as markers. Biotechnol Advances, 27: 84-93.

[34] Nobuhiro S., Mittler R. 2006. Reactive oxygen species and temperature stresses: a delicate balance between signaling and destruction. Physiologia Plantarum, 126: 45-51.

[35] Beyer W.F., Fridovich I. 1987. Assaying for superoxide dismutase activity: some large consequences of minor changes in conditions. Analytical Biochemistry, 161 (2): 559-66. 
[36] Lee Y.L., Yen M.T., Mau J.L. 2007. Food Chemisrty, 104 (1): 1-9.

[37] Sarvajeet S.G, Narendra T. 2010. Reactive oxygen species and antioxidant machinery in a biotic stress tolerance in crop plants. Plant Physiology and Biochemistry, 3: 1-22.

[38] Jaiswal S.K, Gupta V.K, Ansari M.D., Siddiqi N.J., Sharma B. 2017. Vitamin C acts as a hepatoprotectant in carbofuran treated rat liver slices in vitro. Toxicology Reports, 9 (4): 265-273.

[39] Choudhury S., Panda P., Sahoo L., Panda S.K. 2013. Reactiveoxygen species signaling in plants under abiotic stress. Plant Signaling and Behavior, 8: e23681.

[40] Genestra M. 2007. Oxyl radicals, redox-sensitive signaling cascades and antioxidants. Cell. Signalling, 19: 1807-1819.

[41] Jeong J.B., Park J.H., Lee H.K., Ju S.Y., Hong S.C., Lee J.R., Chung G.Y., Lim J.H., Jeong H.J. 2009. Protective effect of the extracts from Cnidium officinale against oxidative damage induced by hydrogen peroxide via antioxidant effect. Food and Chemical. Toxicology, 47: 525-529.

[42] Del Río L.A., Corpas F.J., López-Huertas E., Palma J.M. 2018. Plant Superoxide Dismutases: Function Under Abiotic Stress Conditions. In: Gupta D., Palma J., Corpas F. (eds) Antioxidants and Antioxidant Enzymes in Higher Plants. Springer, Cham.

[43] Scandalios J.G. 1993. Oxygen stress and superoxide dismutases. Plant Physiology, 101: 7-12.

[44] Kim FJ, Kim HP, Hah YC, Roe JH. 1996. Differential expression of superoxide dismutases containing Ni and Fe/Zn in Streptomyces coelicolor. Europan Journal of Biochemistry, 241: 178185.

[45] Kirecci O.A. 2018. The Effects of Salt Stress, SNP, ABA, IAA and GA Applications on Antioxidant Enzyme Activities in Helianthus annuus L. Fresenius Environmental Bulletin, 27 (5A): 3783-3788.

[46] Tuna A.L., Kaya C., Dikilitas M., Higgs D. 2008. The combined effects of gibberellic acid and salinity on some antioxidant enzyme activities, plant growth parameters and nutritional status in maize plants. Environmental and Experimental Botany, 62: 1-9.

[47] Upadhyaya H., Panda S.K., Dutta B.K. 2008. Variation of physiological and antioxidative responses in tea cultivars subjected to elevated water stress followed by rehydration recovery. Acta Physiologiae Plantarum, 30: 457-468.

[48] Bowler C., Montagu M.V., Inze D. 1992. Superoxide dismutase and stress tolerance. Annual Review of Plant Physiology and Plant Molecular Biology, 43: 83-116.

[49] Ferreira R.R., Fornazier R.F., Vitoria A.P., Lea P.J., Azevedo R.A. 2002. Changes in antioxidant enzyme activities in soybean under cadmium stress. Journal of Plant Nutrion, 25: 327-342.

[50] Cemeli E., Baumgartner A., Anderson D. 2009. Antioxidants and the comet assay. Mutation Research, 681: 51-67.

[51] Gill S.S., Tuteja N. 2010. Reactive oxygen species and antioxidant machinery in abiotic stress tolerance in crop plants. Plant Physiology and Biochemistry, 1-22.

[52] Akkuş İ. 1995. Serbest radikaller ve fizyopatolojik etkileri. Mimoza yayınları, Kuzucular ofset, Konya.

[53] Gutteridge J.M. 1995. Lipid peroxidation and antioxidants as biomarkers of tissue damage. Clinical Chemistry, 41: 1819-1828.C.L.

[54] Fattman, L.M., Schaefer, T.D. 2003 Oury. Extracellular superoxide dismutase in biology and medicine. Free Radical Biology and Medicine, 35 (3): 236-256.

[55] Srivalli B., Chinnusamy V., Khanna-Chopra R. 2003 Antioxidant defense in response to abiotic stresses in plants. Journal of Plant Biology, 30: 121-139.

[56] Ben-Amor N., Hamed K.B., Debez A., Grignon C., Abdelly C. 2005. Physiological and antioxidant response of the perennial halophytes Crithmum maritimum to salinity. Plant Science, 168: 889-899.

[57] Willekens H., Villarroel R., Van Montagu M., Inzé D., Van Camp W. 1994. Molecular identification of catalases from Nicotiana plumbaginifolia (L.). FEBS Letters, 352: 79-83.

[58] Van Breusegem F., Vranova E., Dat .JF., Inzé D. 2001. The role of active oxygen species in plant signal transduction. Plant Science, 161: 405-414.

[59] Sekmen A.H., Türkan I., Takio S. 2007. Differential responses of antioxidative enzymes and lipid peroxidation to salt stress in salt-tolerant Plantago maritima and salt-sensitive Plantago media. Physiologia Plantarum, 131: 399-411. 
[60] Vital S.A., Fowler R.W., Virgen A., Gossett D.R., Banks S.W., Rodriguez J. 2008. Opposing roles for superoxide and nitric oxide in the $\mathrm{NaCl}$ stress-induced upregulation of antioxidant enzyme activity in cotton callus tissue. Environmental and Experimental Botany, 62: 60-68.

[61] Zhang Y., Yang J., Lu S., Cai J., Guo Z. 2008. Overexpressing SgNCED1 in tobacco increases aba level, antioxidant enzyme activities, and stress tolerance. Journal of Plant Growth and Regulation, 27: 151-158.

[62] Yu Q., Osborne L.D., Renge Z. 1999. Increased tolerance to Mn deficiency in transgenic tobacco overproducing superoxide dismutase. Annals of Botany, 84: 543-547.

[63] Dixon D.P,. Cummins L., Cole D.J., Edwards R. 1998. Glutathione-mediated detoxification systems in plants. Current Opinion in Plant Biology, 1: 258-266.

[64] Ledford H.K., Chin B.L., Niyogi K.K. 2007. Acclimation to singlet oxygen stress in Chlamydomonas reinhardtii. Eukaryotic Cell, 6: 919-930.

[65] Blokhina O., Virolainen E., Fagerstedt., K.V. 2003. Antioxidants, oxidative damage and oxygen deprivation stress: a review. Annals of Botany, 91 (2): 179-194.

[66] Kangasjarvi S., Lepistö A., Hännikäinen K., Piippo M., Luomala E.M., Aro E.M., Rintamäki E. 2008. Diverse roles for chloroplast stromal and thylakoidbound ascorbate peroxidases in plant stress responses. Biochemistry Journal, 412: 275-285.

[67] Noctor G, Foyer C.H. 1998. Ascorbate and glutathione: keeping active oxygen under control. Annual Review of Plant Physiology and Plant Molecular Biology, 49: 249-279.

[68] Miyake C., Asada K. 1992. Thalakoid bound ascorbate peroxidase in Spinach chloroplasts and photoregeneration of its primary oxidation product monodehydroascorbate radicals in thalakoids. Plant Cell Physiology, 33: 541-553.

[69] Miyake C.., Cao WH., Asada K. 1993. Purification and molecular properties of ascorbate bound peroxidase in spinach chloroplasts. Plant Cell Physiology, 34: 881-889.

[70] Rosa S.B., Caverzan A., Teixeira F.K., Lazzarotto F., Silveira J.A.G., Ferreira-Silva S.L., AbreuNeto J., Margis R., Margis-Pinheiro M. 2010. Cytosolic APx knockdown indicates an ambiguous redox responses in rice. Phytochemistry, 71 (5-6): 548-558.

[71] Caverzan A., Bonifacio A., Carvalho F.E.L., Andrade C.M.B., Passaia G., Schünemann M., Maraschin F.S., Martins M.O., Teixeira F.K., Rauber R., Margis R., Silveira J.A.G., MargisPinheiro M. 2010. The knockdown of chloroplastic ascorbate peroxidases reveals its regulatory role in the photosynthesis and protection under photo-oxidative stress in rice. Phytochemistry, 1 (56): 548-558.

[72] Caverzan A., Passaia G., Rosa S.B., Ribeiro C.W., Lazzarotto F., Margis-Pinheiro M. 2012. Plant responses to stresses: role of ascorbate peroxidase in the antioxidant protection. Genetics and Molecular Biology, 35 (4): 1011-1019.

[73] Dalal M., Khanna-Chopra R. 2001. Differential response of antioxidant enzymes in leaves of necrotic wheat hybrids and their parents. Physiologia Plantarum, 111: 297-304.

[74] Sudhakar C., Lakshmi A., Giridarakumar S. 2001. Changes in the antioxidant enzyme efficacy in two high yielding genotypes of mulberry (Morus alba $\mathrm{L}$.) under $\mathrm{NaCl}$ salinity. Plant Science, 16: 613-619.

[75] Eltayeb A.E., Kawano N., Badawi G.H., Kaminaka H., Sanekata T., Shibahara T., Inanaga S., Tanaka K. 2007. Overexpression of monodehydroascorbate reductase in transgenic tobacco confers enhanced tolerance to ozone, salt and polyethylene glycol stresses. Planta, 225: 1255-1264.

[76] Chen Z., Gallie D.R. 2006. Dehydroascorbate reductase affects leaf growth, development, and function. Plant Physiology, 142: 775-787.

[77] Anjum N.A., Gill S.S., Gill R., Hasanuzzaman M., Duarte A.C., Pereira E., Ahmad I., Tuteja R., Tuteja N. 2014. Metal/metalloid stress tolerance in plants: role of ascorbate, its redox couple, and associated enzymes. Protoplasma, 251 (5): 1265-1283.

[78] Jimenez A., Hernandez J.A., del Rio L.A., Sevilla F. 1997. Evidence for the presence of the ascorbate- glutathione cycle in mitochondria and peroxisomes of pea leaves. Plant Physiology, 114 (1): 275-284.

[79] Leterrier M., Corpas F.J., Barroso J.B., Sandalio L.M., del R1o L.A. 2005. Peroxisomal monodehydroascorbate reductase. Genomic clone characterization and functional analysis under environmental stress conditions. Plant Physiology, 138 (4): 2111-2123. 
[80] Asada K. 1999. The water-water cycle in chloroplasts: scavening of active oxygens and dissipation of excess photons. Annual Review of Plant Physiology and Plant Molecular Biology, 50: 601-639.

[81] Horemans N., Foyer C.H., Asard H. 2000. Transport and action of ascorbate at the plant plasma membrane. Trends in Plant Science, 5: 263-267.

[82] Smirnoff N. 2000. The role of active oxygen in the response of plants to water deficit and desiccation. New Phytologist, 125: 27-58.

[83] Smirnoff N. 2011. Vitamin C: the metabolism and functions of ascorbic acid in plants. Advances in Botanical Research. In: Rebeille F, Douce R, editors. Biosynthesis of Vitamins in Plants: Vitamins B6, B8, B9, C, E, K, Part 2. 1st edn. USA: Academic Press; 107-177.

[84] Foyer C.H., Noctor G. 2005. Oxidant and antioxidant signaling in plants: a reevaluation of the concept of oxidative stress in a physiological context. Plant Cell Environment. 28: 1056-1071.

[85] Sharma P., Jha A.B., Dubey R.S., Pessarakli M. 2012. Reactive oxygen species, oxidative damage, and antioxidative defense mechanism in plants under stressful conditions. Journal of Botany, 1-26.

[86] Wu Y.S., Tang K.X. 2004. MAP Kinase cascades responding to environmental stress in plants. Acta Botanica Sinica, 46: 127-136.

[87] Hare P.D., Cress W.A., Staden J.V. 1998. Dissecting the roles of osmolyte accumulation during stress. Plant Cell Environment, 21: 535-553.

[88] Igamberdiev A.U., Hill R.D. 2004. Nitrate, NO and haemoglobin in plant adaptation to hypoxia: an alternative to classic fermentation pathways. Journal of Experimenthal Botany. 55: 2473-2482.

[89] Noctor G. 2006. Metabolic signalling in defence and stress: the central roles of soluble redox couples. Plant Cell Environment, 29: 409-425.

[90] Kruk J., Holländer-Czytko H., Oettmeier W., Trebst A. 2005. Tocopherol as singlet oxygen scavenger in photosystem II. Journal of Plant Physiology, 162: 749-757.

[91] Boo Y.C., Jung J. 1999. Water deficit induced oxidative stress and antioxidative defenses in rice plants. Journal of Plant Physiology, 51: 255-261.

[92] Shao H.B., Chu L.Y., Wu G., Zhang J.H., Lu Z.H., Hu Y.C. 2007. Changes of some anti-oxidative physiological indices under soil water deficits among 10 wheat (Triticum aestivum) genotypes at tillering stage. Biointerfaces, 59: 113-119.

[93] Shao H.B, Chen X.Y., Chu L.Y., Zhao X.N., Wu G., Yuan Y.B., Zhao C.X., Hu Z.M. 2006. Investigation on the relationship of Proline with wheat anti-drought under soil water deficits. Biointerfaces, 53: 113-119.

[94] Wu G., Wei Z.K., Shao H.B. 2007. The mutual responses of higher plants to environment: physiological and microbiological aspects. Biointerfaces, 59: 113-119.

[95] Millar A.H., Mittova V., Kiddle G., Heazlewood J.L., Bartoli C.G., Theodoulou F.L., Foyer C.H. 2003. Control of ascorbate synthesis by respiration and its implications for stress responses. Plant Physiology, 133: 443-447.

[96] Noctor G., Gomez L., Vanacker H., Foyer C.H. 2002. Interactions between biosynthesis, compartmentation and transport in the control of glutathione homeostasis and signalling. Jourbal of Experimenthal Botany, 53: 1283-1304.

[97] Ahmad P.,, Cheruth A.J., Mohamed A.S, Gowher N., Satyawati S. 2010. Roles of enzymatic and nonenzymatic antioxidants in plants during abiotic stress. Critical Reviews in Biotechnology, 30 (3): 161-175.

[98] Schroeter H., Boyd C., Spencer J.P., Williams R.J., Cadenas E., Rice-Evans C. 2002. MAPK signaling in neurodegeneration: influences of flavonoids and of nitric oxide. Neurobiology of Aging, 23: 861-880.

[99] Rice-Evans C.A., Miller N.J., Paganga G. 1997. Antioxidant properties of phenolic compounds. Trends in Plant Science, 2: 152-159. 